\title{
VISIONARY LEADERSHIP IN THE ADMINISTRATIVE STAFF OF THE GUAPAN EDUCATIONAL UNIT
}

\author{
Oscar Antonio Martinez Molina iD \\ Universidad Nacional de Educación (Ecuador) \\ oscar.martinez@unae.edu.ec
}

Received February 2018

Accepted March 2018

\section{Abstract}

The purpose of the present study lies in determining the visionary leadership manifest in the administrative staff of the Guapan Educational Unit, with the research taking the form of a positivist descriptive research study that will deepen the knowledge of the variable that concerns us: visionary leadership. Through the application of field designs, the information was obtained directly from interaction with the subjects, who made up a population of (62) subjects, among whom were (07) administrators and (55) educational professionals, with the sample consisting of 38 instructors. The instrument used was an 18-item multiple-choice questionnaire (Almost always, Sometimes and Almost never), which was validated by three experts, with a reliability of 0.97 , which demonstrates that it is highly reliable. The consolidation of this research showed with its results that the administrative staff engages in visionary leadership in the Guapan Educational Unit. The opinion of the instructional staff, however, shows just the opposite, judging that the administrators show weakness in visionary leadership. For this reason, guidelines are offered to the administrators of the state-funded private school located in the Cañar province, Azogues district, Guapan parish

Keywords - Management, Visionary leadership, Educational administration.

\section{Introduction}

According to Arenas (2009: page78), visionary leadership in educational administration "is the set of abilities and skills developed by the leader in order to motivate in an influential manner his/her collaborators in order to achieve innovation within the organization, based on openness to change". On a similar note, being visionary on an organizational level is associated with the administrator's capacity to consolidate with his/her collaborating team the reforms, changes and new paradigms that respond to the future projection, having the capacity to motivate them in the development of their competences, with these serving as the source of the effectiveness that is required these days in educational institutions.

In an educational scenario, the development of visionary leadership commits the administrative staff to exercising influences on the actors that work alongside them, in order to ensure the use of the best techniques and methods for education. It should be added that one of the conditions for visionary leadership consists of innovation.

In Ecuador, an imperative need for educational change has been seen, acknowledging the reforms promoted by the Ministry of Education (2010) in the update to the Basic Education curriculum. Therefore, the proposal from the administrative body for education in the country that administrative staff engages in visionary leadership is understandable. The objective is to promote and encourage the transformations that generate a new 
organizational culture with predomination of the incorporation of ICTs in the educational process in order to achieve the digitalized interaction in learning how to learn.

According to the considerations set out here, the administrative staff fosters the development of visionary leadership in order to coincide with the contemporary guidelines, for which it is necessary to be proactively inspirational with the teaching staff, and in doing so, strengthen the educational interaction through the application of technology. This constitutes a strategic line of professional updating for teaching performance.

This research is located in the Guapan parish of the Azogues district in the province of Cañar, Ecuador. Starting in the year (2015-2016), professional development processes have been promoted in an effort to modernize education. These provide important experience to the knowledge and know-how constructed within the schools.

In this context, Álvarez (2011), in studies conducted in Bolivian schools in the municipality of Motatán in the state of Trujillo, Venezuela, shows the scarce level of development of visionary leadership. Evidence of this perception corresponds to the lack of sensitivity of the leader and communication processes with limitations. All of this may be due to the fact that leadership of educational administrators is characterized by a disruptive linear model. This focus considers the changes that are a priority to implement in educational institutions.

Contextualizing the situation/problem according to Agustín (2014), in the public primary institutions in district No. 09-0102 of the urban area of Quetzaltenango, Guatemala, the concern of the informants is manifested by considering that the reality in these institutions would seem to be similar to what has already been proposed; the source of this perception is based on observations made in the context, informal conversations and the personal experience of the researcher. All of this leads to the inference that in these schools, the educational administration, due to a lack of visionary leadership, engages in little proactive inspiration and its orientations lack a systematic process in which the development of skills is promoted in the application of technology.

From this derives the importance of conducting this research on visionary leadership and information and communications technology in the regular education school located in the province of Cañar, in the district of Azogues, in the parish of Guapan, which will enable us to expand our knowledge of the topic. It is based on this that the question arises that will serve to guide the research.

How does the administrative staff engage in visionary leadership in the school belonging to the Azogues district?

The purpose being sought after is to determine the visionary leadership of the administrative staff of the regular education school located in the Cañar province, in the Azogues district, in the Guapan parish.

The research to be conducted is focused on the regular education school located in the Cañar province, in the Azogues district, in the Guapan parish. The period is the 2015-2016 school year, with a population of 62 informants, divided between 07 administrators and 55 teachers.

For Hernández, Fernández and Baptista (2008: page132), the theoretical bases "are the foundations of the subject matter that is approached through the variables, giving rise to analysis and interpretation". In other words, the theoretical references are included that will serve as the basis for the study of the visionary leadership variables and the information and communications technologies (ICTs), within the scope of the present research.

Upon analyzing visionary leadership, Crespo (2010: page 29) defines it as "a quality that often transcends organizations; it is those leaders who maintain a set of skills that enables them to guide a team defined by its union and charismatic attitude". In this context, for it to be successful, it must help join or overcome 
the differences that threaten to break apart an organization; the activation of this natural cohesion helps employees and collaborators work harder than they did before.

In short, visionary leadership can be defined as a style that basically recognizes patterns, the style of an apprentice who directs processes in which the strategies and visions can emerge spontaneously or be conceived in a deliberate manner. In this way, these leaders include those who model the strategies, as they are concentrated in the domain as the result of the detail, rapport with their ideas and emphasis on dedication, combined with their experience and a certain touch of harmony. The challenge of visionary leadership consists of being able to overcome the symbiosis of the exclusive personal relationship with their ideas (Zalazar, 2012).

Taking into consideration the proposals by Crespo (2010: page 33), the motivating nature in visionary leadership "makes it possible to build on a continuous basis and develop new perspectives to awaken in others enthusiasm for an idea". In other words, identification with their projects, the need to accompany them in their goals, development of a particularly innovative vision of reality.

By virtue of this, when the personal characteristics with the determinants are in the presence of motivational leadership, beliefs are established about life, the institution, the country and knowledge, among other things. Nonetheless, being motivating, developing a positive attitude in collaborators, is a task that represents a gradual, cumulative and sustained process; it is not an easy task. Demotivation can come about instantly, toppling in a matter of seconds the work of many people over a long time.

According to Piqueras (2014: page 1), proactive inspiration from the scope of visionary leadership "is to manage, thanks to a very inspiring vision and your commitment to it, to transmit this vision to people and to cause them to be loyal to it. A visionary leader is the type of person who can move the masses". In this context, visionary leaders, by being proactively inspiring, must collaborate with their team to establish a plan and specify a vision for the institution. Once the team understands what it must do, the leader must provide confidence and inspire them to do a job, without constantly being with them.

On a similar note, it should be stressed that visionary leaders are often not aware of the impact of many of their negative behaviors. This inspires the first challenge, which is to be aware of these matters. The second is to do away with the behaviors that are contrary to inspiration. Consequently, among the most common mistakes in these behaviors are: a lack of energy and enthusiasm, absorbing and consuming energy instead of injecting it into the group; for them work is just work, as opposed to an opportunity to do something with meaning. Weak leaders do not inspire and are not proactive; they do not excite others or generate enthusiasm on their team (UNESCO, 2000).

That said, as proposed by Moreno (2009: page 13), effective communication "not only requires knowing the process of communication in a comprehensive manner, but also establishing mechanisms that ensure that the message we want to transmit reaches the receiver correctly and that through feedback we can ensure that the message was successfully received". In other words, we are talking about effective communication when the message the sender transmits is studied and understood by the receiver and when immediate feedback is provided. Effective communication can be interpersonal, from person to person, as well as intergroup, organizational and external.

By interpreting the visionary leadership role as that of a systematic guide in the motivation process, Hernández (2009: page 79), refers to it as:

"an internal change agent that involves, on the one hand, placing value on the training received that qualifies him/her as an agent facilitating change in the school. On the other hand, asking the question of how this professional can collaborate to generate a culture of improvement, boost the capacity for change and optimize the learning of the school community to guarantee the quality of learning". 
As a result, reconsidering his/her work to transform him/her in an educational leader in the schools as a systematic guide enables him/her to guide the teacher's work towards student improvement and motivate them all to achieve the mission and vision of the educational organization.

From the perspective of Carrera (2007: page 82), "it is to successfully transform an idea into reality". This type of characteristics in visionary leaders causes their collaborators to find other ways of achieving the objectives in their daily activities. In this vein, innovation is necessary to make the organization an institution that is open to change, reforming new paradigms. Innovation in the leadership of the administrative staff represents a strength of sharing new experiences within the institution; this means updating processes and procedures found within the institution.

Based on these proposals, being innovative in the context of visionary leadership means being open to change, delegating functions, promoting skills and engaging in continuous updating. This is supported below.

According to Ortiz (2010: page 123), openness to change represents "a challenge, must be considered bidirectionally, not just one-way; it is a stimulating challenge for both the administration and the collaborator; if both parties manage to overcome it, growing in intellectual terms, this generous openness will permit the organization to prevail and grow", facing the changing environment with openness and appropriately flowing with it. In this sense, openness to change can be understood as facing life with a positive mentality; in particular, being open to the possibility of changes is fundamental to bring everything to a happy ending and for it to be successful.

Interpreting the delegation of functions, Musso (2009: page 76) understands that "it is a transfer of tasks, functions, attributes and authority, which is carried out between a person who holds a higher position and a subordinate, for the latter to operate in a limited, bounded field, normally with a specific objective". According to this, authority is understood as the right to give orders to another person or persons who belong to the institution and who depend on the person holding said authority in order to act or not act, in this way permitting the goals and objectives to be reached that form part of the work provided for by the person delegating it.

It should be pointed out that in the field of educational organizations, the process is governed by the educational administrator or director of the institution. The person doing the delegating does not have the mindset to fully exercise his or her functions (he/she would be dismissed). Subject to this and in light of this decision, he/she must select the indicated person (delegate). The healthy practice is then to inform them and their superiors in writing, explaining the task that will be taken on.

\section{Methodology}

The research conducted was descriptive in nature; in this regard, Arias (2007: page 47) specifies that descriptive research "is that which makes it possible to characterize events, phenomena, weaknesses that occur in an organization or community and where both the existing reality and the way things should be are verified through informants and documentary research".

Specifically, the present descriptive research was carried out in the regular education school located in the province of Cañar, in the Azogues district, in the Guapan parish, where the level of visionary leadership by the administrative staff was determined. Also, through the broadening of knowledge, a contribution is consolidated, such as specific recommendations for administrative staff on visionary leadership and the application of information and communications technology.

The design applied was that of a field study, which means the information was obtained on-site, i.e., at the regular education school in Guapan. In this sense, Arias (2007: page 50) believes that the design of a study "is the general strategy that the researcher uses to apply in the environment where the problem occurs and thus obtain precise, effective information". Likewise, Arias (2007: page 61) specifies that the "design of a 
study are the conditions that are present in the reality that is being investigated, making it possible to collect and analyze data to know the reality being studied".

In this study, data was collected using the survey technique, through the application of the questionnaire to the population of administrators and teachers at the regular education school located in the Cañar province, Azogues district, Guapan parish.

In this scenario, reference is made to the group of people in the environment studied. Hurtado (2009: page 79) considers the population to be "the group for which the conclusions were valid that were obtained to the elements or units studied by virtue of the characteristics of the variables subject to study". Once the field of study is defined, from the perspective of a population or universe, it can refer to any group of elements intended to be researched to find out about their characteristics. In this case, the population was made up by 62 teachers, of whom 7 are administrators.

In the present context, the sample is a subgroup of the population; however, Hurtado (2009: page 84) believes that the sample "is a small part of the population studied, and it must be characterized by being representative of the population". Likewise, Balestrini (2009: page 125) says that "a sample must be defined based on the determined population, and the conclusions drawn from said sample can only refer to the referenced population". In other words, it refers to a number of scientifically selected individuals or objects, each of which was an element in the universe. The sample subject to this study was made up of 38 teachers.

Hernández et al. (2008: page 59) indicate "this is used when we wish to obtain data or information; the application of a technique leads to obtaining information, which must be saved using a data collection instrument". In this scenario, Arias (2007: page 54) states that "the technique is the set of rules and procedures that enable the researcher to establish the relationship to the object or subject of study".

Likewise, the technique is a methodological guide, scientifically aimed to collecting information. Furthermore, it has been stated that the study was conducted using a survey technique. In this regard, according to the criteria of Tamayo y Tamayo (2005: page 210), the survey "is an instrument of observation formed by a series of questions that make it possible to ensure a holistic view of the existing problem". In other words, it refers to visionary leadership and the application of information and communications technology promoted by the administrative staff belonging to the Guapan Education Unit to which the study was limited.

According to Hernández et al. (2008: page 66), "they constitute the natural means through which it is possible to obtain and file information pertinent to the topic being studied". In other words, it is the means used by the researcher to measure the behavior or attribute of the variable. Likewise, Arias (2007: page 59) considers that "the instruments are written resources to collect the necessary input for the research".

With regard to the instrument, a multiple-choice (Almost always, Sometimes and Almost never) questionnaire consisting of (18) items was written, based on the indicators proposed on the variable map and supported by the theoretical framework, according to the bibliography review, which made it possible to obtain reliable information from the subjects.

In the course of this research, a series of stages were carried out aimed at standardizing the procedures carried out by the researcher.

First of all, an inquiry was conducted into the issues present at the institution being studied in order to carry out the approach and formulation of the problem, delimit it and justify it, as well as establish the variables, dimensions and indicators; the bibliographic review was then conducted, aimed at supporting the theoretical framework of the research. 
Secondly, the work targeted the methodological design of the research, taking into account the type, design and population, as well as the technique and instrument to be applied. In this sense, two questionnaires were written, which were subjected to the validity and reliability process, based on expert opinion.

Thirdly, the pertinent data were collected according to the following procedures: design and debugging of the instrument; creation of the instrument; validation of the instrument; personal interview with the staff at the institution and informing them about the purpose of the study; formal request of permission; collaboration for the application of the instrument; application of the instrument; and collection, organization and classification of the data issued by the population of the state-funded private school in Guapan.

\section{Analysis and interpretation of the results}

The results obtained are the product of having studied the units of analysis, in this case, the teachers at the state-funded private school in Guapan.

Visionary leadership from the perspective of the educational administration processes includes four aspects: school administration, supervision, planning and academic administration, which the directors and teachers responded to according to the evaluation conducted.

The description of leadership considered, on a personal and social level, in the processes of educational administration is related to the mission, vision and objectives: in other words, understanding the graphs based on the opinions of the administrators and teachers means analyzing the responses provided on the questionnaire. In this section, the items are analyzed that are considered relevant in terms of the conclusions drawn.

The following point uses contingency tables to show the distribution of the total population of 62 subjects that make up the institution during the academic year September 2015-July 2016, between the administrative and teaching staffs. For this study, a sample of 38 teachers was considered who participated in the application of the survey on the perception of the qualities that the subjects must have in the development of visionary leadership.

From the information regarding the administrative and teaching staffs, according to Table 1 , it is acknowledged that visionary leadership is learned $97 \%$ of the time, although potentialities and strengths may exist, such as skills and qualities in the social integration process, charisma being understood as the natural quality or gift that a person has to attract others.

\begin{tabular}{|c|c|c|c|}
\hline Perception & Almost never & Sometimes & Almost always \\
\hline Charisma & $0 \%$ & $3 \%$ & $97 \%$ \\
\hline Being an excellent teacher & $0 \%$ & $14 \%$ & $86 \%$ \\
\hline $\begin{array}{l}\text { Good appearance, good personal presentation } \\
\text { and empathy are important for visionary } \\
\text { leadership }\end{array}$ & $0 \%$ & $62 \%$ & $38 \%$ \\
\hline Interpersonal intelligence & $0 \%$ & $38 \%$ & $62 \%$ \\
\hline Social sensitivity, peer issues & $0 \%$ & $48 \%$ & $52 \%$ \\
\hline
\end{tabular}

Table 1. Perception of the sample (of 38 subjects) regarding the visionary leadership qualities of administrators and teachers

In Table 2, it can be seen that the participation of teachers in the programming of actions that stimulate the success of the participation, socialization and teamwork represent a high percentage of collaborative work, fostered by empathy and affectivity, in which each member of the group has the opportunity to express his or her feelings, tastes, emotions and personal, family and work concerns in order to find support, solidarity and commitment. 


\begin{tabular}{|c|c|c|c|c|}
\hline Items & Question & Almost never & Sometimes & Almost always \\
\hline 1 & $\begin{array}{l}\text { Teachers have the opportunity to participate } \\
\text { in the drafting of the school's mission and } \\
\text { vision }\end{array}$ & $9 \%$ & $23 \%$ & $68 \%$ \\
\hline 2 & $\begin{array}{l}\text { Teachers participate in the programming of } \\
\text { actions to promote the identity, principles } \\
\text { and values to apply them in the school }\end{array}$ & $0 \%$ & $14 \%$ & $86 \%$ \\
\hline 3 & $\begin{array}{l}\text { Teachers participate in the creation of } \\
\text { strategic objectives in the school's planning }\end{array}$ & $0 \%$ & $13 \%$ & $87 \%$ \\
\hline 4 & $\begin{array}{l}\text { Teachers perceive the administrator-teacher } \\
\text { relationship on equal terms }\end{array}$ & $45 \%$ & $21 \%$ & $34 \%$ \\
\hline 5 & $\begin{array}{l}\text { Teachers perceive the administrator-teacher } \\
\text { relationship in an authoritarian manner }\end{array}$ & $27 \%$ & $12 \%$ & $61 \%$ \\
\hline 6 & $\begin{array}{l}\text { Teachers perceive a favorable climate for } \\
\text { teamwork, which permits finding the solution } \\
\text { to problems }\end{array}$ & $12 \%$ & $25 \%$ & $62 \%$ \\
\hline 7 & $\begin{array}{l}\text { Teamwork is promoted among teachers in } \\
\text { order to generate good management and } \\
\text { communication practices within the school }\end{array}$ & $0 \%$ & $28 \%$ & $72 \%$ \\
\hline 8 & $\begin{array}{l}\text { Teachers are frequently supervised in order } \\
\text { to monitor the planning, management and } \\
\text { execution process within the school }\end{array}$ & $0 \%$ & $0 \%$ & $100 \%$ \\
\hline 9 & $\begin{array}{l}\text { Educational and visionary leadership is } \\
\text { promoted as a competence of educational } \\
\text { administration among teachers }\end{array}$ & $26 \%$ & $35 \%$ & $39 \%$ \\
\hline 10 & $\begin{array}{l}\text { Teachers have participated in the decision- } \\
\text { making at the school }\end{array}$ & $16 \%$ & $20 \%$ & $60 \%$ \\
\hline 11 & $\begin{array}{l}\text { Teachers participate in proposing training } \\
\text { needs and priorities to improve education at } \\
\text { the school }\end{array}$ & $6 \%$ & $18 \%$ & $76 \%$ \\
\hline 12 & $\begin{array}{l}\text { Teacher training activities are carried out to } \\
\text { improve the teaching-student learning } \\
\text { processes, taking into consideration ICT }\end{array}$ & $11 \%$ & $21 \%$ & $68 \%$ \\
\hline 13 & $\begin{array}{l}\text { Training and updating of teachers is } \\
\text { promoted as an improvement process in the } \\
\text { educational administration. }\end{array}$ & $10 \%$ & $18 \%$ & $72 \%$ \\
\hline
\end{tabular}

Table 2. Results of the administered survey (2017)

Figure 1 shows how the teaching staff of the school considers that visionary leaders have attributes that correspond to their attitude. Accordingly, the impression is linked to the image created by the follower, using reasonable logic, which enables him/her to develop a stereotype in relation to the characteristics that a visionary leader must have.

There are thus certain attributes that must be considered when being an inspirational leader, such as: radius of trust, influence without authority, empathy and social skills, which will contribute to the image transmitted to followers; since there are no leaders without followers, it is important to emphasize that leadership does not depend solely on the leader, but also on the followers.

Teachers have the opportunity to participate in the creation of the school's mission and vision; this is according to $68 \%$ of the results obtained from the 62 teachers surveyed, of whom 7 are administrators.

On the other hand, teachers participate in the programming of actions to promote the identity, principles and values to be applied in the school; $86 \%$ of the teachers and administrators consulted state they agree with the participation in activities related to the programming of actions to promote the identity, principles and values.

Teachers also participate in the development of strategic objectives in school planning; $87 \%$ always participate in school planning and 13\% participate positively in one way or another in the establishing of 
the objectives, which let them know about the planning, organization, management and execution processes for the actions at the Guapan school.

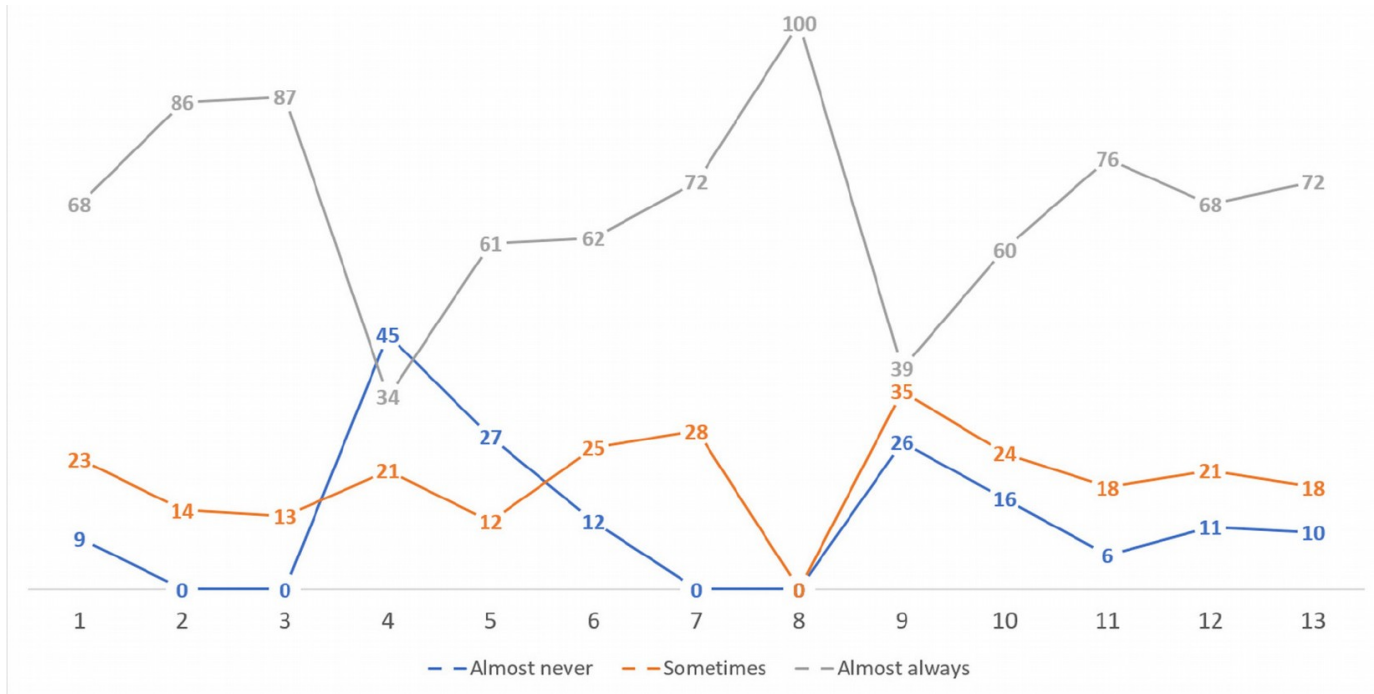

Figure 1. Results obtained from the applied instrument (2017)

The teachers perceive the administrator-teacher relationship on equal terms; $34 \%$ of those surveyed agree that an equal relationship exists, to which $21 \%$ can be added, while $45 \%$ indicate that no equal terms exist.

$61 \%$ of the teachers perceive that the administrator-teacher relationship is a good one, in order to achieve the established objectives.

In terms of the organizational climate, $12 \%$ feel that there is not a favorable climate; $62 \%$ believe that the development of good relationships among peers is fundamental, which indicates that the climate is favorable for promoting the culture of team work.

Teamwork is promoted among teachers in order to generate good management and communication practices within the school; $72 \%$ of the teachers consulted agree that they receive instructional guidance to improve the teaching-learning process with students and to establish good communications practices; $28 \%$ can be added to this group, which indicates that developing processes to support teachers makes it possible to improve the educational dynamics and interpersonal relations among peers and between them and the students.

$100 \%$ of the teachers stated they totally agreed with the processes of supervision, planning, management and execution of the activities planned at the school, which shows that the continuity in the supervision processes is fundamental to implement advisory actions.

Furthermore, $39 \%$ of the teachers consulted stated that they agree with the educational and visionary leadership processes in the educational administration, while 35\% can be added to this process of active learning.

In relation to decision-making, $60 \%$ of the teachers surveyed agree that they participate in the decisionmaking, to which we can add $24 \%$ that believe that they sometimes participate; this means that the participation of teachers in the decision-making is important in order to know the status of the school.

Likewise, $76 \%$ agree with the participation of the teachers to identify training needs and priorities, reinforced by $18 \%$; this shows that the participation of teachers is fundamental in decision-making, in order to prioritize the training processes. 
Teacher training is undoubtedly a fundamental activity in order to improve the teacher training activity. In this regard, $68 \%$ of the teachers surveyed indicated that they agree with the teacher training; this indicates that the development of training constitutes an improvement in the teaching-learning processes.

Finally, $72 \%$ of the teachers consulted state they agree with the training and updating of teachers in order to improve the educational administration; this means that it is currently fundamental to promote professional training and updating to improve the instruction and the improvement processes in educational administration.

From the results obtained, it is significant to note that most of the items show a high percentage of teachers who agree with the importance of participating in the formation of the mission, vision and objectives, permitting a level of institutional belonging; this is confirmed by $68 \%$ of the teachers, who feel that their participation contributes to the processes of strategy planning in the context of academic administration, which makes it possible to implement changes in the educational development of the school.

On the other hand, it is important to observe that $86 \%$ of the teachers consulted agree with participation in the programming of activities in order to promote the identity, principles and values that represent a fundamental element to achieve changes in the administration of the school.

The perception of equality of conditions in school administration is a fundamental element in the personal and institutional relations, as supported by $55 \%$ of the teachers. This result is considered important for the development of the change process in the context of the organizational climate, which validates the visionary leadership in the school, which in turn strengthens the good relations between the administrator-teacher in order to achieve the established objectives, in the interests of strengthening the established objectives.

From the above, we can see that $87 \%$ of those consulted consider it fundamental to promote the culture of team work in order to achieve the desired level of success on any project, in the search for solutions to problems at the school; nearly 100\% agreed with the need to participate in support processes to improve the educational dynamics and interpersonal relationships among peers.

This result is reaffirmed by the fact that the majority of the teachers agree with the supervision processes in the planning, management and execution of the activities planned at the school: this demonstrates the continuity in the supervision processes is crucial to develop the actions and advisement that permits decision-making in most of them in terms of achieving the objectives proposed for the classroom teaching process.

From the information obtained, it can be determined that $39 \%$ of the teachers consulted state that they agree with the promotion of visionary leadership in educational administration, while $39 \%$ are added to this share with active learning; we should note that this style of leadership is considered important to promote change in the administration processes to obtain effective results in the school.

Along the lines of these ideas, $60 \%$ of those consulted agree with the participation in decision-making; this means that the participation of teachers in decision-making is important to know the status of the school and successfully engage in the change process in the educational administration of the school.

Another aspect that is considered important to promote visionary leadership is the proposal of training and educational needs and priorities, in which $76 \%$ of the teachers consider that the training processes must be prioritized in order to obtain better results to improve the organizational climate.

This result is supported by the opinion of $68 \%$ of the teachers, who indicate they agree with the teacher training; this shows that the development of training contributes to the improvement of the teaching-learning processes of the students. 
On the other hand, $72 \%$ of those consulted state that it is currently crucial to promote professional training and updating to improve the teaching efforts and educational administration.

Finally, it can be said that visionary leaders have more than just charisma. Visionary leaders have the ability to create and articulate a realistic, credible and attractive vision of the future that emerges from and improves upon the present. This vision differs from other forms of administration established in different ways in that it is prospective and innovative.

\section{Conclusions}

By describing visionary leadership of the administrative staff for the purposes of this study, motivation was considered as an element stimulating the achievement of this quality in leaders. In this regard, the following results were obtained: with regard to the opinion of the administrators, they believed to be sensitizing, inspirational, proactive, effective communicators and providers of systematic guidance.

In this same context, the teachers with their opinions maintained the tendency that the administrative staff assumes in its actions postures to sensitize them to improve their performance based on the requirements of the vision and mission for the future, inspiring them to do better in fulfilling their responsibility to educate students. However, they contradict the administrators in terms of the implementation of effective communication, considering that in some situations, the issuance and transmission of given specifications present communication barriers. This is a situation that is similar to their role as systematic providers of guidance, since in their answers they do not coincide with the statements made by the administrators, aspiring to have continuous guidance from the organizational administration.

From the perspective of innovation, the results of the responses by the administrators were that they are open to change, delegate functions, promote teacher skills and foster continuous updating; all of this from the focus of visionary leadership.

Contrasting the positions expressed in this regard, the teachers in their responses show divergent criteria, considering that, in relation to openness to change and the delegation of functions, the statement made by the administrators does not appear to correspond to reality, in that their actions are not aimed at this administrative innovation, as suggested by visionary leadership. Meanwhile, in relation to being promoters of skills and fostering permanent updating, the administrators assume these postures with the staff, developing their influence through leadership.

With respect to the teachers, they manifest opinions opposite to those of the administrators in relation to the administration's stand on engaging in the social promotion of the institution, applying information and communications technology. It is worth noting, in turn, the trend in terms of the administrators' opinion that the schools have proper information through technology tools, generating a new organizational culture and thus strengthening the school-community interaction.

In summary, visionary leadership must be consolidated in school organizations in order to motivate and innovate in benefit of educational interaction, favoring the training of students and promoting institutional interaction in the portrayal of the school as a place of shared experiences, based on creativity and scientific and technological progress.

\section{Declaration of Conflicting Interests}

The author declared no potential conflicts of interest with respect to the research, authorship, and/or publication of this article.

\section{Funding}

The author received no financial support for the research, authorship, and/or publication of this article. 


\section{References}

Agustín, G. (2014). Liderazgo docente y disciplina en el aula. Guatemala: Universidad Rafael Landívar.

Álvarez, S. (2011). Liderazgo visionario del director en la planificación por proyectos. Trabajo especial de grado. Valera, Venezuela: Universidad Valle de Momboy.

Arenas, R. (2009). Liderazgo visionario del gerente educativo. México: Asociación Oaxaqueña de Psicología. AC.

Arias, F. (2007). Metodología de la investigación social (2nd ed.). México: Editorial McGraw-Hill.

Balestrini, M. (2009). Metodología de la investigación social (2nd ed.). México: Editorial McGraw-Hill.

Carrera, O. (2007). El lider como innovador (3rd ed.). Barcelona, Spain: Editorial Vértice.

Crespo, M. (2010). El líder del siglo XXI (2nd ed.). Bogotá, Colombia: Editorial Continental.

Hernández, C. (2009). El docente como orientador (2nd ed.). Caracas, Venezuela. Editorial: Panojo. S.A.

Hernández, R., Fernández, C., \& Baptista, P. (2008). Metodología de la investigación bolística (3rd ed.). Caracas, Venezuela: Sypal.

Hurtado, J. (2009). El Proyecto de Investigación e Introducción a la Metodologia cientifica (5th ed.). Caracas, Venezuela: Editorial Episteme.

Ministerio de Educación (2010). Actualización Curricular. Quito, Ecuador: Gobierno Nacional de la República del Ecuador. Available at: https://educacion.gob.ec/actualizacion-curricular/

Moreno, L. (2009). Comunicación Efectiva para el Logro de una Visión Compartida. CULCyT, May-June, 6(32).

Musso, F. (2009). Como se delegan las tareas en la orientación sus beneficios (2nd ed.). Buenos Aires, Argentina: Editorial Produmedios.

Ortiz, J. (2010). La apertura al cambio como nuevo paradigma organizacional (2nd ed.). Bogotá, Colombia: Editorial Continental Editores.

Piqueras, C. (2014).6 estilos de lideraqgo. Goleman. España: Excélitas S.L. Available at: https://www.cesarpiqueras.com/6-estilos-de-liderazgo-goleman/

Tamayo y Tamayo, M. (2005). El proyecto de investigación. Medellín, Colombia: Universidad de Antioquia. Available at: http://aprendeenlinea.udea.edu.co/lms/moodle/course/view.php?id=637

UNESCO (2000). Desafios de la educación. Instituto Internacional de planeamiento de la educación. IIPE. Available at: http://unesdoc.unesco.org/images/0015/001591/159155s.pdf

Zalazar, R.. (2012). Introducción a la administración: Paradigmas en las organizaciones. Available at: https://ebookcentral.proquest.com

Published by OmniaScience (www.omniascience.com)

Journal of Technology and Science Education, 2018 (www.jotse.org)

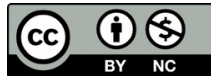

Article's contents are provided on an Attribution-Non Commercial 4.0 Creative commons International License. Readers are allowed to copy, distribute and communicate article's contents, provided the author's and JOTSE journal's names are included. It must not be used for commercial purposes. To see the complete licence contents, please visit https://creativecommons.org/licenses/by-nc/4.0/. 